\title{
Alfred de Musset, Il ne faut jurer de rien, Un Caprice
}

\section{Valentina Ponzetto}

\section{(2) OpenEdition}

\section{Journals}

\section{Edizione digitale}

URL: http://journals.openedition.org/studifrancesi/34933

DOI: 10.4000/studifrancesi.34933

ISSN: 2427-5856

\section{Editore}

Rosenberg \& Sellier

\section{Edizione cartacea}

Data di pubblicazione: 1 novembre 2005

Paginazione: 435

ISSN: 0039-2944

\section{Notizia bibliografica digitale}

Valentina Ponzetto, «Alfred de Musset, II ne faut jurer de rien, Un Caprice», Studi Francesi [Online], 146

(XLIX | II) | 2005, online dal 30 novembre 2015, consultato il 18 avril 2021. URL: http://

journals.openedition.org/studifrancesi/34933 ; DOI: https://doi.org/10.4000/studifrancesi.34933

\section{Questo documento è stato generato automaticamente il 18 avril 2021.}

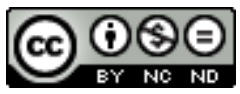

Studi Francesi è distribuita con Licenza Creative Commons Attribuzione - Non commerciale - Non opere derivate 4.0 Internazionale. 


\title{
Alfred de Musset, Il ne faut jurer de rien, Un Caprice
}

\author{
Valentina Ponzetto
}

\section{NOTIZIA}

ALFRED DE MUSSET, Il ne faut jurer de rien, Un Caprice, édition présentée par SYLVAIN LEDDA, Paris, Bordas, 2004, pp. 215.

1 A riunire in questa nuova edizione per i tipi di Bordas, semplice e dichiaratamente scolastica, ma accurata, Il ne faut jurer de rien e Un Caprice, non è solo la natura di proverbes de salon e la prossimità cronologica delle due opere, composte rispettivamente nel 1836 e nel 1837, ma anche una comunanza di tematiche, di stile, e, per così dire, di inserimento nel contesto sociale e letterario della Francia post-1830.

Entrambe, infatti, mettono in scena i salotti della buona società del regno di LuigiFilippo, colti sul vivo nelle loro abitudini, nel loro linguaggio e nei loro intrattenimenti mondani, dal ballo, al teatro, al gioco, ed entrambe riflettono l'influenza delle mode letterarie e teatrali del tempo, in parte integrate da Musset nella propria scrittura, in parte garbatamente sbeffeggiate attraverso citazioni più o meno esplicite e rovesciamenti delle convenzioni sceniche in uso. Seconda Sylvain Ledda, inoltre, entrambe testimoniano dell'atteggiamento di Musset nei confronti della realtà che lo circonda, atteggiamento fatto di pessimismo, insoddisfazione e disincanto che si traducono, per reazione, in una forma di disimpegno e di rifiuto. Questo si manifesta da un lato nell'apparente superficialità del dandismo, e dall'altro nella fuga in una forma letteraria, il proverbe, e in una tipologia sociale, un'aristocrazia per molti aspetti ancora legata all'Ancien Régime, che rinviano al secolo precedente. Dal punto di vista formale e stilistico, tuttavia, Musset reinventa il genere settecentesco del proverbe, facendone una delicata commedia di costume e puntando essenzialmente sul ritmo serrato del dialoghi, sulla loro vivacità brillante, sempre piena di spirito e naturalezza, sulla singolarità e la profondità dei personaggi, mai caricaturali, pur quando risultano 
ridicoli. Fra i temi, accanto a quello sociale e mondano di pittura del bel mondo del tempo, il critico sottolinea soprattutto quello dell'amore e del rapporto fra i sessi, trattato per la prima volta nel teatro di Musset in modo più leggero e meno pessimista, aperto al lieto fine, ma pur sempre conflittuale e imprevedibile.

3 L'apparato scolastico di accompagnamento ai testi comprende, oltre ad una succinta biografia di Musset, una tabella riassuntiva della struttura di ogni pièce, brevi brani di altre opere contemporanee incentrati sulle tematiche messe in luce dall'analisi, e, alla fine di ogni scena, una pagina con proposte di esercizi di scrittura per gli studenti, che spaziano dall'analisi tematica, a quella testuale a quella drammaturgica, senza dimenticare le più concrete problematiche di mise en scène. 